\title{
Cellular Senescence Is Associated with Faster Progression of Focal Segmental Glomerulosclerosis
}

\author{
Daniela Verzola ${ }^{a}$ Michela Saio $^{a}$ Daniela Picciotto ${ }^{a}$ Francesca Viazzi $^{\mathrm{a}}$ \\ Elisa Russo ${ }^{a}$ Leda Cipriani $^{a}$ Annalisa Carta ${ }^{a}$ Francesca Costigliolo $^{a}$ \\ Gabriele Gaggero $^{b}$ Gennaro Salvidio $^{a}$ Pasquale Esposito ${ }^{a}$ \\ Giacomo Garibotto $^{\text {a }}$ Laura Poggi $^{a}$
}

aDivision of Nephrology, Dialysis and Transplantation, Department of Internal Medicine and IRCCS Ospedale Policlinico San Martino, University of Genova, Genova, Italy; ${ }^{b}$ Division of Pathology, IRCCS Ospedale Policlinico San Martino, University of Genova, Genova, Italy

\section{Keywords}

Cell senescence $\cdot$ Focal segmental glomerulosclerosis ·

Chronic kidney disease

\begin{abstract}
Background: A current, albeit unproven, hypothesis is that an acceleration of cellular senescence is involved in impaired renal repair and progression of glomerular diseases. Focal segmental glomerulosclerosis (FSGS) is a glomerular disease with a substantial risk for progression to ESRD. However, if and to what extent cell senescence predicts a negative outcome in FSGS is still unknown. Methods: The hypothesis that cell senescence represents a proximate mechanism by which the kidney is damaged in FSGS (NOS phenotype) was investigated in 26 consecutive kidney biopsies from adult FSGS cases (eGFR $72 \pm 4 \mathrm{~mL} / \mathrm{min}$, proteinuria $2.3 \pm 0.6 \mathrm{~g} /$ day) who were incident for 2 years in a Northern Italian nephrology center and had a 6-year clinical follow-up. Results: Cell senescence ( $p 16^{\mathrm{INK} 4 \mathrm{~A}}$, SA- $\beta$-galactosidase [SA- $\beta$-Gal]) was upregulated by $\sim 3$ - to 4 -fold in both glomerular and tubular cells in kidney biopsies of FSGS as compared to age-matched controls $(p<0.05-0.01)$. Tubular SA- $\beta-$ Gal correlated with
\end{abstract}

proteinuria and glomerulosclerosis, while only as a trend, tubular p $16^{\mathrm{INK} 4 \mathrm{~A}}$ was directly associated with interstitial fibrosis. At univariate analysis, basal eGFR, proteinuria, and tubular expression of SA- $\beta$-Gal and $p 16^{\mathrm{NK} 4 \mathrm{~A}}$ were significantly directly related to the annual loss of eGFR. No correlation was observed between glomerular p $16^{\mathrm{INK} 4 \mathrm{~A}}$ and eGFR loss. However, at multivariate analysis, eGFR, proteinuria, and tubular p16 ${ }^{\text {INK4A }}$, but not SA- $\beta-G a l$, contributed significantly to the prediction of eGFR loss. Conclusions: The results indicate that an elevated cell senescence rate, expressed by an upregulation of $\mathrm{p} 16^{\mathrm{INK} 4 \mathrm{~A}}$ in tubules at the time of initial biopsy, represents an independent predictor of progression to ESRD in adult patients with FSGS.

(c) 2021 S. Karger AG, Basel

\section{Introduction}

Aging is associated with accelerated cell senescence, a stress-response process during which cells undergo an irreversible cycle arrest and produce a proinflammatory secretory phenotype [1-3]. In several chronic diseases, including diabetes and obesity, senescent cells accumulate in tissues, where their inflammatory phenotype disrupts

karger@karger.com
www.karger.com/ajn
Karger $V^{\prime /}$

Giacomo Garibotto

Division of Nephrology, Dialysis and Transplantation, Department of Internal Medicine Università di Genova and IRCCS Ospedale Policlinico San Martino

Viale Benedetto XV, 6, IT-16132 Genoa (Italy)

gari@unige.it 
structure and function, inducing fibrosis and, possibly, cancer $[3,4]$.

A current, albeit unproven, hypothesis is that an acceleration of cell senescence is involved in impaired renal repair and progression of glomerular diseases [3-5]. In a seminal study performed in 35 patients affected by different glomerular diseases, Sis et al. [6] demonstrated an increase in the cycle regulator and tumor suppressor p $16^{\text {INK4A }}$ in the glomeruli, tubules, and interstitium, which correlated with the degree of interstitial fibrosis and tubular atrophy, suggesting a role for somatic cell senescence as a mediator of progression of glomerular diseases. In addition, we previously observed that $\mathrm{p} 16^{\mathrm{INK} 4 \mathrm{~A}}$ and senescence-associated $\beta$-galactosidase (SA- $\beta$-Gal) were markedly upregulated in both the glomeruli and tubuli in diabetic nephropathy and correlated with several clinical parameters of metabolic stress [7]. More recently, Liu et al. [8] showed an upregulation of $\mathrm{p} 16^{\mathrm{INK} 4 \mathrm{~A}}$ in renal tubular cells that correlated with the expression of collagen III in IgA nephropathy.

Focal segmental glomerulosclerosis (FSGS) is a common glomerular disease with a substantial risk of progression to ESRD [9]. In addition to the pathognomonic segmental glomerular sclerosing lesions, the renal histopathology in progressive FSGS is characterized by widespread tubular atrophy and interstitial fibrosis, and both proteinuria and the extent of tubulointerstitial disease correlate well with the degree of functional renal impairment $[10,11]$. Despite recent progress in our understanding of genetic and environmental factors in the pathogenesis of FSGS [11-14] and in the molecular pathways that can differentiate etiologically distinct subtypes, translating basic research into clinical care appears to be insufficient [13-15]. Although cross-sectional studies have demonstrated an upregulation of somatic senescence in glomerular diseases, including FSGS [6], the functional role of the changes observed is unknown, and whether senescence is really associated with more disease progression is still not understood. A better knowledge of the role played by cell senescence in FSGS, and of the different cell types involved by this process, may be helpful also in view of the new "senolytic" therapies which, by eliminating accumulated senescent cells, could potentially recover tissue function [16].

In this study, we tested the hypothesis that acceleration of senescence represents a relevant mechanism by which the kidney is injured in FSGS. With this in mind, we studied the expression of 2 different markers of senescence, p $16^{\text {INK4A }}$ and SA- $\beta$-Gal, in kidney biopsies from a cohort of incident adult FSGS patients who were as for the standard of care followed up for 6 years.
Table 1. Clinical characteristics of FSGS subjects.

\begin{tabular}{lc}
\hline Number of subjects & 26 \\
Age, years & $52(21)$ \\
Gender, M/F & $12 / 14$ \\
BMI, $\mathrm{kg} / \mathrm{m}^{2}$ & $25(9)$ \\
Proteinuria, g/day & $2.3 \pm 0.6$ \\
eGFR, mL/min $1.73 \mathrm{~m}^{2}$ & $72 \pm 7$ \\
SBP, mm Hg & $138 \pm 21$ \\
DBP, mm Hg & $82 \pm 9$ \\
Globally sclerosed glomeruli, \% & $10 \pm 3.8$ \\
Interstitial fibrosis, \% & $17 \pm 3.7$ \\
Tubular atrophy, \% & $8 \pm 2.8$ \\
Serum albumin, g/dL & $3.5(3)$ \\
Total cholesterol, mg/dL & $207(118.5)$ \\
Triglycerides, mg/dL & $157(152)$ \\
eGFR loss, mL/min/year & $4.7 \pm 1.55$ \\
Follow-up, years & $6 \pm 0.56$
\end{tabular}

Data are mean \pm SEM or median (IQR). FSGS, focal segmental glomerulosclerosis; eGFR, estimated glomerular filtration rate; SBP, systolic blood pressure; DBP, diastolic blood pressure.

\section{Methods}

Patients

Cell senescence was investigated in 26 consecutive kidney biopsies from FSGS patients who were incident from May 2007 to June 2009 at the Department of Internal Medicine, Nephrology Division, Genoa University, and IRCCS AOU San Martino, Genoa, Italy. All biopsies were not for research but for clinical diagnosis. The inclusion and exclusion criteria were defined to select cases with FSGS as the primary disease. During the screening, 12 FSGS cases were not included in the analysis because they were recognized to be affected by a secondary disease. The procedures were in accordance with the Declaration of Helsinki. The study was part of a larger study on aging and the kidney sponsored by the Ministero dell'Università e della Ricerca Scientifica (MIUR) (Progetti Finalizzati per la Ricerca di Base-FIRB 2002) and approved by the Ethical Committee of the Department of Internal Medicine [7, 17]. All kidney biopsy specimens were analyzed by the same renal pathologist (Dr. Gennaro Salvidio). The morphologic changes in kidney biopsies were considered for the following categories: glomerular sclerosis (global/segmental), glomerular cellularity, interstitial fibrosis, interstitial inflammation, tubular atrophy, and atherosclerosis. All the included cases belonged to the not otherwise specified FSGS subtype [13]. Normal portions of kidney tissue from nephrectomies for renal carcinoma $(n=13,8$ males and 5 females, $60 \pm 4$ years) were examined as a control group.

Baseline clinical and demographic characteristics of subjects are shown in Table 1. The average protein excretion was $2.3 \pm 0.6$ $\mathrm{g} /$ day; 5 subjects presented with nephrotic ( $>3 \mathrm{~g}$ /day) proteinuria. The mean eGFR was $72 \pm 7 \mathrm{~mL} / \mathrm{min} 1.73 \mathrm{~m}^{2}$. In FSGS, the percentages of globally sclerosed glomeruli, tubular atrophy, and interstitial fibrosis were $10 \pm 3.8,8 \pm 3$, and $17 \pm 3.7 \%$, respectively. In control tissue, the percentages of globally sclerosed glomeruli, tubular atrophy, and interstitial fibrosis were $3 \pm 1,5 \pm 2$, and $4 \pm 1 \%$, 


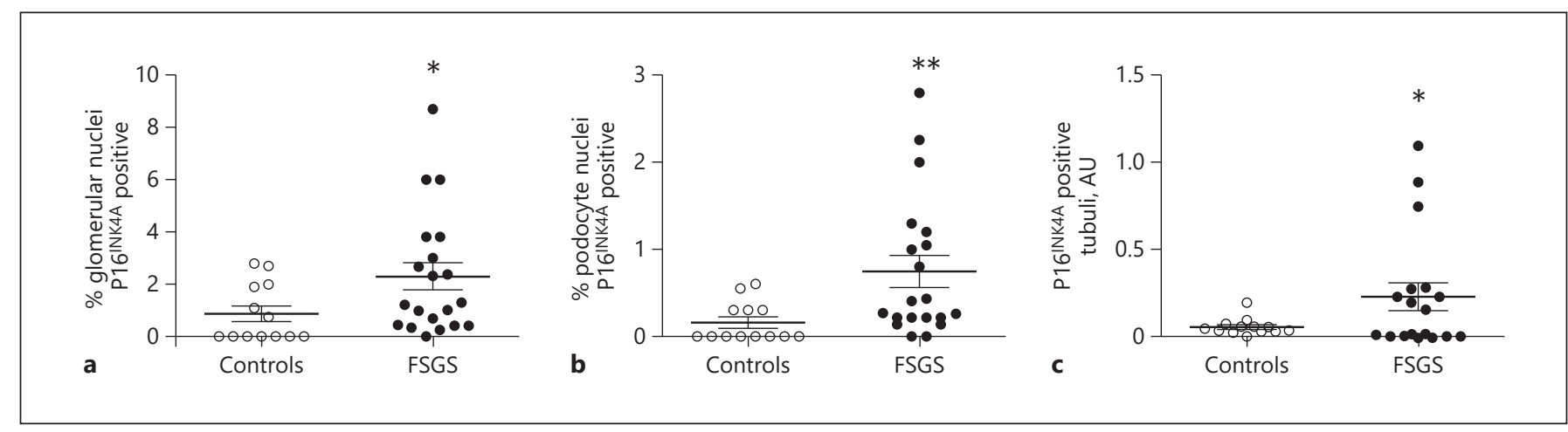

Fig. 1. Expression of $\mathrm{p} 16^{\mathrm{INK} 4 \mathrm{~A}}$ in the glomeruli and tubulointerstitium of control subjects and patients with FSGS. The percentage of glomerular p16 ${ }^{\mathrm{INK} 4 \mathrm{~A}}$-positive nuclei (a), as well as the percentage of podocyte $\mathrm{p} 16^{\mathrm{INK} 4 \mathrm{~A}}$-positive nuclei (b), was higher in pa- tients with FSGS than in controls. FSGS patients showed also a strikingly increased p16 ${ }^{\mathrm{INK} 4 \mathrm{~A}}$ expression in tubuli (c). ${ }^{*}=p<0.05$ or less; ${ }^{* *}=p<0.01$ or less versus controls. FSGS, focal segmental glomerulosclerosis; AU, arbitrary units. respectively. Routine clinical visits, including clinical labs, proteinuria, and eGFR (CKD-epi) estimate, were carried out basally, after 1-3 months, and then at least annually for 6 years. These results represent collection from standard practice. All but 1 subject received single or double RAS blockade. Fifteen subjects received steroids/immunosuppressive therapy. Seven of 26 patients $(28 \%$ of cases) doubled their serum $\mathrm{Cr}$ or reached ESRD at the end of follow-up. The mean eGFR loss per year was $4.7 \pm 1.55 \mathrm{~mL} / \mathrm{min}$.

\section{Expression of Nuclear p16 ${ }^{I N K 4 A}$ and $S A-\beta-G a l$}

SA- $\beta$-Gal-positive cells were detected in frozen tissue as described by Dimri et al. $[18,19]$ as cells showing a bright cytoplasmic blue precipitate. Samples were analyzed for $\mathrm{p} 16^{\mathrm{INK} 4 \mathrm{~A}}$ as previously described [17]. Paraffin sections $(5 \mu \mathrm{m})$ of $2 \%$ paraformaldehyde-fixed renal biopsies were deparaffinized, hydrated, and treated with $3 \%$ methanol hydrogen peroxide solution. Slides were exposed to primary antibody for $1 \mathrm{~h}$ (1:100 dilution in PBS), followed by incubation in biotinylated anti-rabbit antibody $(1: 100$ dilution in PBS) for 30 min. At least 5 (range 5-10) glomeruli from each biopsy were systematically serially sectioned to estimate cell number by light microscopy. Positive glomeruli were defined by the presence of at least 1 positive nucleus/cell. The percentage of p16 $6^{\mathrm{INK} 4 \mathrm{~A}}$-positive nuclei (nuclear $\mathrm{p} 16^{\mathrm{INK} 4 \mathrm{~A}}$ ) was assessed for glomeruli and tubules and expressed as percent positive cells. On average, 900 glomerular and 1,300 tubular nuclei were counted. The nuclear cytoplasmic expression of $\mathrm{p} 16^{\mathrm{INK} 4 \mathrm{~A}}$ in tubules was examined by image analysis and expressed as percent positive areas [17]. SA- $\beta$-Gal tubular cytoplasmic staining was assessed by counting the percentage of tubular cross sections that showed positive cytoplasmic staining. For immunofluorescence studies, slides were incubated with anti-podocin and anti-p16 ${ }^{\text {INK4A }}$ and subsequently with Alexa Fluor ${ }^{\circledR} 594$ goat anti-rabbit IgG and Alexa Fluor ${ }^{\circledR} 488$ goat anti-rabbit IgG.

\section{Reagents}

5-Bromo-4-chloro-3-indolyl- $\beta$-D-galactopyranoside was purchased from Merck Group (Milano, Italy), antihuman polyclonal p16 ${ }^{\text {INK4A }}$ Ab was obtained from Santa Cruz Biotechnology (DBA Italia s.r.l., Seregno, Italy) and from St John's Laboratory (DBA
Italia s.r.l.), the biotin-streptavidin-amplified detection system was from Vector Laboratories Inc. (DBA, Italia s.r.l.), and DAB and Eukitt were from Merck Group. Anti-podocin, Alexa Fluor ${ }^{\circledR} 594$ goat anti-rabbit IgG, and Alexa Fluor ${ }^{\circledR} 488$ goat anti-rabbit IgG were purchased from Thermo Fisher Scientific (Milan, Italy).

\section{Statistical Analysis}

Data are presented as means \pm SEM. Parameters not normally distributed were logarithmically transformed for statistical analysis and expressed as median (interquartile range). The Statview statistical package (Cary, NC, USA) was used for the analysis. Comparisons between groups were made by ANOVA. Comparisons of proportions were made using the $\chi^{2}$-test or Fisher's exact test whenever appropriate. Relationships between parameters were analyzed using simple regression analysis or the Spearman test, as required. Multivariate logistic regression analysis was performed to assess which parameters significantly related in the simple regression analysis were independent predictors of eGFR loss at follow-up. A 2-tailed $p$ value $<0.05$ was considered statistically significant.

\section{Results}

\section{Cell Senescence Is Upregulated Both in the Glomeruli and in the Tubular Compartment of Patients with FSGS}

In accordance with previous findings $[6,7]$, normal kidneys showed p16 ${ }^{\mathrm{INK} 4 \mathrm{~A}}$ staining in $1.1 \pm 0.57 \%$ of glomerular cells, $1.4 \pm 0.17 \%$ of tubular cells, and $0.2 \pm 0.5 \%$ of vessels. Only scanty interstitial cells were $\mathrm{p} 16^{\mathrm{INK} 4 \mathrm{~A}}$ positive $(0.1 \pm 0.1 \%)$.

The percentage of $\mathrm{p} 16^{\mathrm{INK} 4 \mathrm{~A}}$-positive glomeruli (19.8 \pm 0.5 vs. $13.7 \pm 0.5 \%$ in patients and controls, respectively; $p<0.05)$, as well as the percentage of glomerular $\mathrm{p} 16^{\mathrm{INK} 4 \mathrm{~A}}$ 


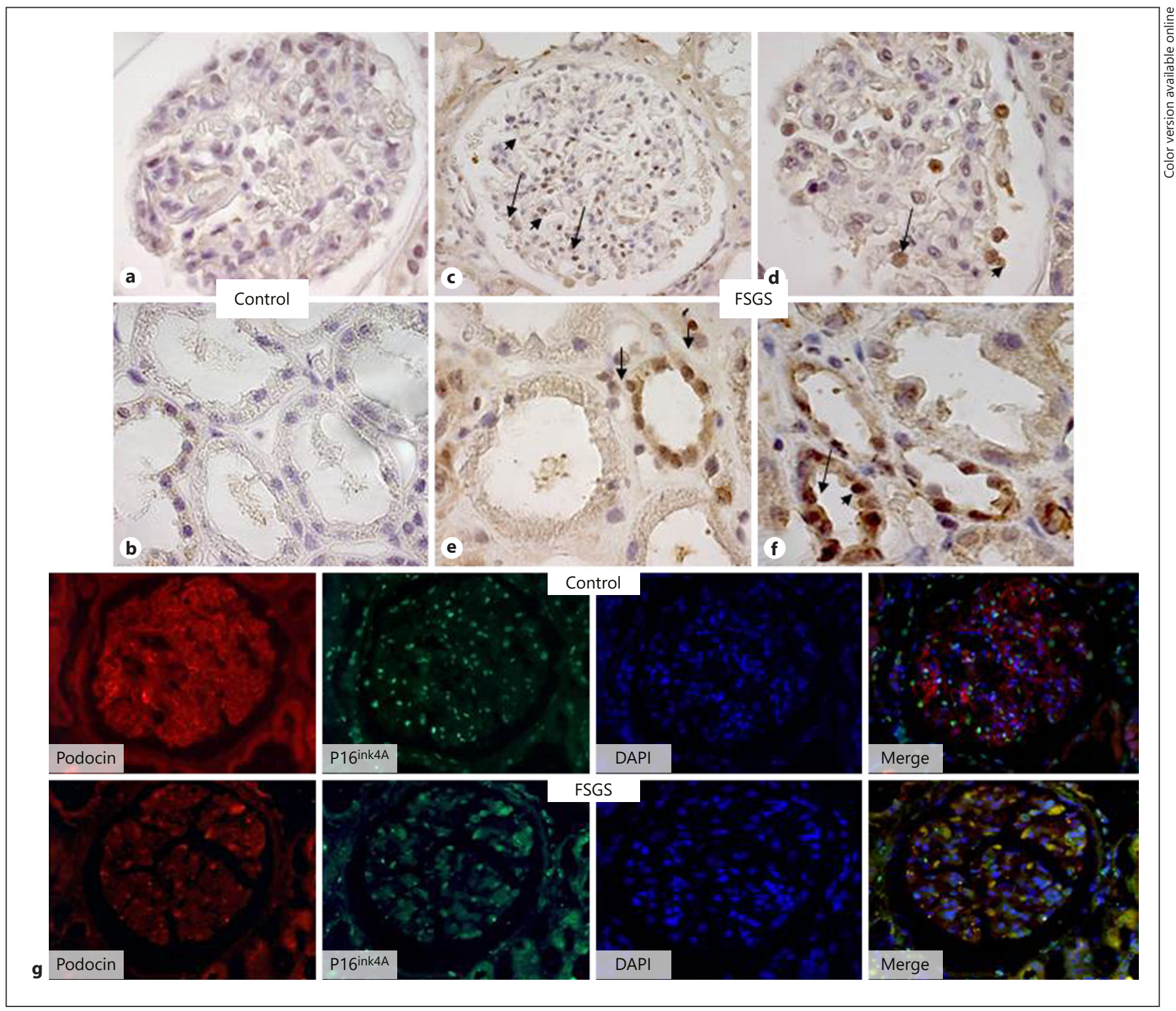

Fig. 2. $\mathrm{p} 16^{\mathrm{INK} 4 \mathrm{~A}}$ in human renal biopsies. Pictures are representative of p16 $6^{\text {INK4A }}$ expression in controls $(\mathbf{a}, \mathbf{b})$ and FSGS $(\mathbf{c}-\mathbf{f})$. p16 ${ }^{\mathrm{INK} 4 \mathrm{~A}}$ was absent or very faintly expressed in controls $(\mathbf{a}, \mathbf{b})$, while it was detectable in the glomeruli of FSGS (c, d). In FSGS,

positive nuclei $(2.28 \pm 0.52$ vs. $1.1 \pm 0.57 \%$ in patients and controls, respectively; $p<0.05$ ), was higher in patients with FSGS with respect to controls (Fig. 1a, 2c, d). Particularly, podocyte nuclear $\mathrm{p} 16^{\mathrm{INK} 4 \mathrm{~A}}$ staining was increased in FSGS $(p<0.02)$ (Fig. 1b, 2c, d) as also depicted in Figure $2 \mathrm{~g}$ representing podocin $/ \mathrm{p} 16^{\mathrm{INK} 4 \mathrm{~A}}$ colocalization. In contrast, the $\mathrm{p} 16^{\mathrm{INK} 4 \mathrm{~A}}$ signal in the arterial vessels was similar to that of the controls (data not shown).

Cell Senescence in FSGS p16 ${ }^{\mathrm{INK} 4 \mathrm{~A}}$ was detected in glomerular cells, such as podocytes $(\mathbf{g})$, and in tubular cells (e-f). g Podocin/p16 ${ }^{\mathrm{INK} 4 \mathrm{~A}}$ co-localization. Arrows indicate positive cells. Magnification, $\times 1,000=(\mathbf{a}) ; \times 400=$ (b-g). FSGS, focal segmental glomerulosclerosis.

FSGS patients showed also a strikingly increased p16 ${ }^{\text {INK4A }}$ expression in tubuli ( 3-fold increase; Fig. 1c, $2 \mathrm{~b}, \mathrm{e}, \mathrm{f})$. Also, $\mathrm{SA}-\beta-\mathrm{Gal}$ staining was approximately 3 -fold higher in the tubular compartment of FSGS than in the controls $(32.6 \pm 17$ vs. $7.35 \pm 5.8 \%$ positive tubuli in patients vs. controls; $p<0.05$ ) (Fig. 3a, b). Upregulation of tubular senescence markers was also observed in FSGS subjects $(n=16)$ displaying mild $(<10 \%)$ interstitial fi- 
Fig. 3. a, b SA- $\beta$-Gal assay was approximately 3 -fold higher $(p<0.05)$ in the tubular compartment of FSGS than in controls. Magnification $\times 200$. SA- $\beta$-Gal, senescence-associated $\beta$-galactosidase; $\mathrm{AU}$, arbitrary units.
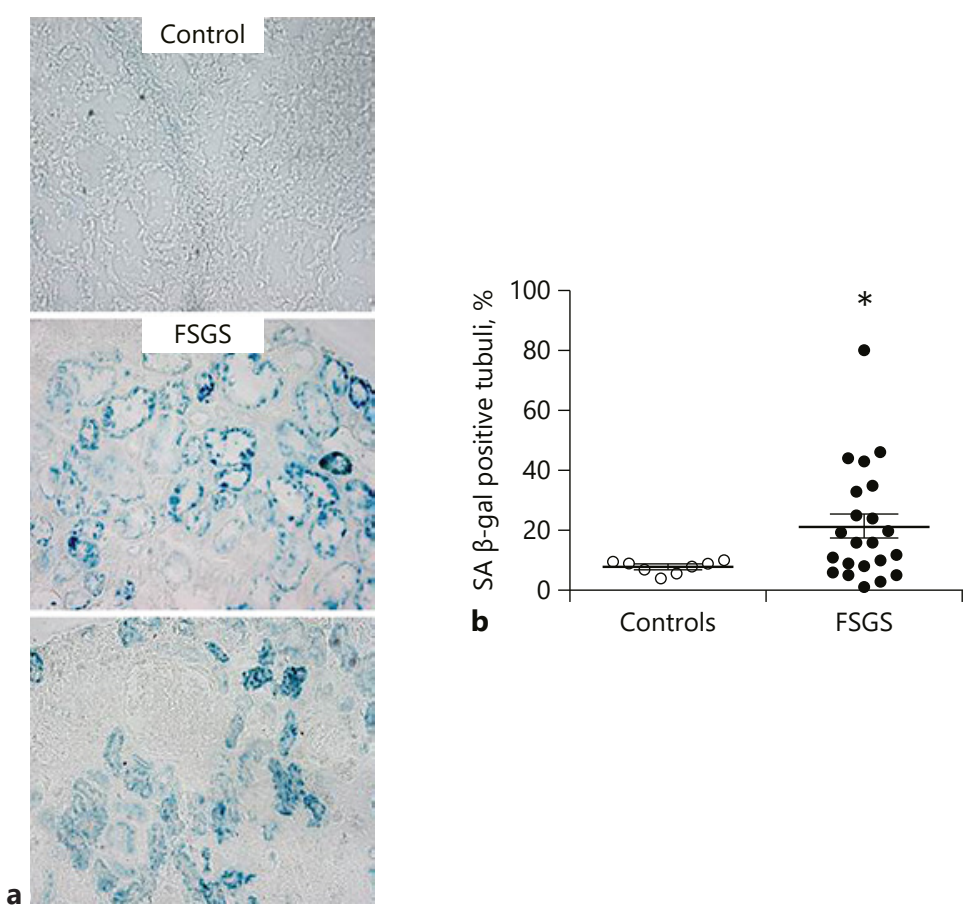

Tubular Cell p16 ${ }^{I N K 4 A}$ in FSGS Is an Early Marker for

Progression

No association between the use of immunosuppressive therapy (steroids/mycophenolate or cyclophosphamide) and eGFR loss was observed $(r=0.17 ; p=0.45)$. At univariate analysis, basal eGFR and proteinuria correlated with eGFR loss at follow-up, in accordance with previous findings [15]. In addition, tubular expressions of both SA- $\beta-G$ al and $p 16^{\mathrm{INK} 4 \mathrm{~A}}$ were significantly directly related to the annual loss of eGFR (Table 4). No correlation was observed between glomerular p16 $6^{\mathrm{INK} 4 \mathrm{~A}}$ and eGFR loss. Using eGFR, proteinuria, age, tubular $16^{\mathrm{INK} 4 \mathrm{~A}}$, and SA$\beta$-Gal for inclusion into multivariate logistic regression analysis models revealed that only eGFR, proteinuria, and tubular p $16^{\text {INK4A }}$ contribute significantly to the prediction of eGFR loss (Table 4).

\section{Discussion}

Expression

When senescence markers were related to individual structural kidney changes (Table 3), we observed that tubular SA- $\beta$-Gal expression was directly associated with glomerulosclerosis and, only as a trend, glomerular p $16^{\mathrm{INK} 4 \mathrm{~A}}$ was directly associated with interstitial fibrosis and atherosclerotic lesions.
Verzola et al. 
Table 2. Associations between clinical findings and senescence marker in the kidney of subjects with FSGS ( $n=$ 26).

\begin{tabular}{|c|c|c|c|c|c|c|}
\hline \multirow[t]{2}{*}{ Clinical finding } & \multicolumn{2}{|c|}{ Glomerular p16 ${ }^{\mathrm{INK} 4 \mathrm{~A}}$} & \multicolumn{2}{|c|}{ Tubular p16 ${ }^{\text {INK4A }}$} & \multicolumn{2}{|c|}{ Tubular SA- $\beta-$ Gal } \\
\hline & $R$ & $p$ value & $r$ & $p$ value & $r$ & $p$ value \\
\hline Age, years & -0.08 & ns & -0.19 & ns & -0.13 & ns \\
\hline Proteinuria, g/day & -0.18 & ns & 0.34 & ns & 0.59 & 0.01 \\
\hline $\mathrm{eGFR}, \mathrm{mL} / \mathrm{min} 1.73 \mathrm{~m}^{2}$ & 0.10 & ns & 0.09 & ns & 0.10 & ns \\
\hline $\mathrm{BMI}, \mathrm{kg} / \mathrm{m}^{2}$ & -0.18 & ns & -0.16 & ns & -0.07 & ns \\
\hline Serum cholesterol, mg/dL & -0.14 & ns & 0.13 & ns & 0.34 & ns \\
\hline Serum triglycerides, $\mathrm{mg} / \mathrm{dL}$ & -0.12 & ns & 0.07 & ns & 0.29 & ns \\
\hline Serum uric acid, mg/dL & 0.28 & ns & -0.40 & ns & -0.21 & ns \\
\hline
\end{tabular}

FSGS, focal segmental glomerulosclerosis; SA- $\beta$-Gal, senescence-associated $\beta$-galactosidase; eGFR, estimated glomerular filtration rate.

Table 3. Associations between structural changes and senescence marker expression in patients with FSGS ( $n=$ 26).

\begin{tabular}{|c|c|c|c|c|c|c|}
\hline \multirow[t]{2}{*}{ Histopathologic change } & \multicolumn{2}{|c|}{ Glomerular p16 $16^{\mathrm{INK} 4 \mathrm{~A}}$} & \multicolumn{2}{|c|}{ Tubular p16 ${ }^{\mathrm{INK} 4 \mathrm{~A}}$} & \multicolumn{2}{|c|}{ Tubular SA- $\beta-$ Gal } \\
\hline & $r$ & $p$ value & $r$ & $p$ value & $r$ & $p$ value \\
\hline Segmental lesions, \% & 0.19 & ns & -0.06 & ns & 0.43 & 0.07 \\
\hline Global sclerosis, \% & -0.14 & ns & 0.15 & ns & 0.59 & 0.01 \\
\hline Glomerular cellularity & -0.19 & ns & 0.26 & ns & -0.05 & ns \\
\hline Interstitial fibrosis & 0.42 & 0.06 & 0.31 & ns & 0.12 & ns \\
\hline Interstitial inflammation & 0.33 & ns & -0.02 & ns & -0.07 & ns \\
\hline Tubular atrophy & 0.29 & ns & 0.14 & ns & 0.34 & ns \\
\hline Atherosclerosis & 0.46 & 0.04 & 0.07 & ns & 0.29 & ns \\
\hline
\end{tabular}

FSGS, focal segmental glomerulosclerosis; SA- $\beta$-Gal, senescence-associated $\beta$-galactosidase.

ease progression. To this aim, we studied the expression of 2 different markers of senescence, SA- $\beta-G a l$ and p16 ${ }^{\mathrm{INK} 4 \mathrm{~A}}$, in 26 consecutive FSGS cases and observed changes in proteinuria and eGFR for 6 years. Three issues are addressed in this study, which bear discussion. The first is the overexpression of both senescence markers, SA- $\beta-$ Gal and $\mathrm{p} 16^{\mathrm{INK} 4 \mathrm{~A}}$, in kidney biopsies of patients with FSGS at the time of diagnosis, a finding that shows that cell senescence is an early mechanism which may play an independent role in kidney damage. The second is the association between the overexpression of the cycle regulator $\mathrm{p} 16^{\mathrm{INK} 4 \mathrm{~A}}$ in the tubular compartment and eGFR loss at the follow-up, a finding which gives strength to the hypothesis that cell senescence accelerates disease progression in FSGS. A third issue is the association between SA- $\beta$-Gal activity in tubular cells and proteinuria, but not with disease progression, which suggests that SA- $\beta-$ Gal activity is more expressive of proteinuria-induced tubular overload than disease progression.

Even as low as $10 \%$ of senescent cells in tissues appear to be sufficient to cause damage and dysfunction [20]. In our study, both the glomeruli and tubuli showed a several-fold increase in senescent markers in FSGS. In the glomeruli, the expression of $\mathrm{p} 16^{\mathrm{INK} 4 \mathrm{~A}}$ showed a podocyte pattern, suggesting that an upregulation of $\mathrm{p} 16^{\mathrm{INK} 4 \mathrm{~A}}$ in glomeruli mainly affects this cell type. Glomerular podocyte depletion has a central role for glomerulosclerosis development [21-23], and increased appearance of podocytes and podocyte constituents in urine is associated with more rapid deterioration of renal function in patients with FSGS [21]. Failure of podocytes to cover the GBM filtration surface area results in denuded areas of GBM, which in turn triggers matrix accumulation and glomerulosclerosis $[22,23]$. Even if podocytes exhibit un- 
Table 4. Regression analysis for eGFR loss in FSGS patients $(n=26)$.

\begin{tabular}{|c|c|c|c|c|c|c|}
\hline \multirow[t]{2}{*}{ Characteristics } & \multicolumn{2}{|c|}{ Univariate model } & \multicolumn{2}{|c|}{ Multivariate model 1} & \multicolumn{2}{|c|}{ Multivariate model 2} \\
\hline & $r$ & $p$ value & $t$ & $p$ value & $t$ & $p$ value \\
\hline Age, years & -0.22 & 0.27 & & & -0.09 & 0.51 \\
\hline $\mathrm{BMI}, \mathrm{kg} / \mathrm{m}^{2}$ & 0.34 & 0.21 & & & & \\
\hline $\mathrm{eGFR}, \mathrm{mL} / \mathrm{min} / 1.73 \mathrm{~m}^{2}$ & 0.45 & 0.02 & 0.49 & 0.003 & 0.36 & 0.021 \\
\hline $\mathrm{SBP}, \mathrm{mm} \mathrm{Hg}$ & 0.28 & 0.26 & & & & \\
\hline $\mathrm{DBP}, \mathrm{mm} \mathrm{Hg}$ & 0.21 & 0.41 & & & & \\
\hline Proteinuria, g/day & 0.59 & 0.002 & 0.40 & 0.016 & 0.34 & 0.02 \\
\hline LDL-cholesterol, mg/dL & 0.11 & 0.33 & & & & \\
\hline Triglycerides, mg/dL & 0.42 & 0.17 & & & & \\
\hline Global glomerulosclerosis, \% & 0.12 & 0.60 & & & & \\
\hline Segmental glomerulosclerosis, \% & -0.17 & 0.47 & & & & \\
\hline Interstitial fibrosis, $\%$ & 0.24 & 0.30 & & & & \\
\hline Interstitial inflammation, $\%$ & -0.19 & 0.42 & & & & \\
\hline Tubular atrophy, $\%$ & 0.23 & 0.23 & & & & \\
\hline Atherosclerosis, \% & -0.13 & 0.58 & & & & \\
\hline p16 $6^{\mathrm{INK} 4 \mathrm{~A}}$ (glomeruli), $\%$ & 0.08 & 0.74 & & & & \\
\hline p16 ${ }^{\text {INK4A }}$ (tubuli), \% & 0.62 & 0.006 & 0.44 & 0.010 & 0.28 & 0.034 \\
\hline SA- $\beta-G a l$ (tubuli), $\%$ & 0.46 & 0.029 & & & -0.20 & 0.19 \\
\hline
\end{tabular}

FSGS, focal segmental glomerulosclerosis; eGFR, estimated glomerular filtration rate (CKD, epi CKD-epi); SBP, systolic blood pressure; DBP, diastolic blood pressure; SA- $\beta$-Gal, senescence-associated $\beta$-galactosidase.

der normal conditions a very low replication, the upregulation of CDK inhibitors could, in theory, lead with time to podocyte loss. However, the functional effect of CDK inhibitors on podocyte replication and loss is not completely recognized. While $\mathrm{p} 16^{\mathrm{INK} 4 \mathrm{~A}}$ has been little studied, podocyte quiescence may require the presence of the CDK inhibitors p27 and p57. In human glomerular diseases, a decrease in p27 and p57 appears to be permissive for an altered proliferative podocyte phenotype [24]. However, in our study, against a functional role of the overexpression of $\mathrm{p} 16^{\mathrm{INK} 4 \mathrm{~A}}$ in glomerular cells, glomerular p16 ${ }^{\mathrm{INK} 4 \mathrm{~A}}$ did not associate neither with worse renal prognosis nor with proteinuria.

Nuclear expression of $\mathrm{p} 16^{\mathrm{INK} 4 \mathrm{~A}}$ and cytoplasmic SA- $\beta$ Gal activity increase with age principally in tubular epithelial cells [25]. As a new finding, data reported here show that in adult FSGS patients with normal or slightly decreased GFR, better than glomerular cell senescence, it is tubular senescence that predicts the loss of renal function. Thus, the degree of tubular p16 ${ }^{\mathrm{INK} 4 \mathrm{~A}}$ in patients with FSGS may represent a negative prognostic factor and a novel marker for progression. Proteinuria and interstitial fibrosis have been shown to predict kidney survival in FSGS $[15,26]$. However, in the earlier stages of the disease, there are a few light microscopy changes that are predictive of the subsequent loss of renal function. In this study, when tubular SA- $\beta$-Gal and p $16^{\text {INK4A }}$ were included in a multiple regression analysis, only tubular $\mathrm{p} 16^{\mathrm{INK} 4 \mathrm{~A}}$ (but not SA- $\beta-\mathrm{Gal}$ ) was found to predict independently the loss of GFR. Thus, an elevated $\mathrm{p} 16^{\mathrm{INK} 4 \mathrm{~A}}$ at the time of initial biopsy comes forth as a novel and independent predictor of the loss of renal function in our cohort of patients with FSGS.

Surprisingly, our study shows that the tubular SA- $\beta$ Gal activity assay, the most commonly used analysis for senescence [27], was not able to predict kidney outcome. Senescent cells express a higher level of lysosomal $\beta$-galactosidase gene (GLB1) and show an increased $\beta$-galactosidase activity at a suboptimal $\mathrm{pH}$ of 6.0 (optimal pH level is 4-4.5), compared to normal cells [18]. It is interesting that in FSGS patients studied here SA- $\beta-\mathrm{Gal}$ was strongly accounted by a high degree of proteinuria at the time of the kidney biopsy, a finding in keeping with the role of proteinuria in inducing lysosome dysfunction in renal tubules [28]. According to our findings, SA- $\beta$ Gal activity appears to better correlate with the tubule overload produced by proteinuria than with the progression of disease.

In our study, we could not find an association between age and cell senescence in FSGS. As a matter of fact, we 
studied an adult population, since younger subjects were not included in the study. In addition, eGFR, as also previously observed in patients with diabetic nephropathy [7], was not related to senescence, suggesting that renal failure per se is not responsible for senescence activation. However, upregulation of cell senescence was already observed in proteinuric patients with normal or subnormal GFR and only modest chronic changes at the time of their biopsy, suggesting that the acceleration of senescence is an early phenomenon.

The mechanism(s) driving cell senescence in the kidney of patients with FSGS cannot be explained by our study. Several cellular stressors, including DNA damage, oxidative stress, RAS induction, and epigenetic mechanisms, induce premature senescence in kidney cells [2932]. The mechanism(s) underlying the effects of the overexpression of $\mathrm{p} 16^{\mathrm{INK} 4 \mathrm{~A}}$ in kidney tubules in FSGS could involve reduced tissue remodeling through different sequential processes, such as a stable proliferative arrest or a secretory phenotype that recruits immune cells and modifies the extracellular matrix and the mobilization of nearby progenitors that repopulate the tissue [3].

Cell senescence is potentially treatable. It has been shown that loss of $\mathrm{p} 16^{\mathrm{INK} 4 \mathrm{~A}}$ attenuates permanent damage, such as interstitial fibrosis and tubular atrophy, and allows for better functional recovery [33]. Therapeutic interventions targeting senescent cells could attenuate FSGS-related renal dysfunction and improve disease outcome. Recently, Baker and colleagues have shown that clearance of $\mathrm{p} 16^{\mathrm{INK} 4 \mathrm{~A}}$ expressing cells extends lifespan and attenuates age-dependent glomerulosclerosis [34].

This study has some limitations. Our cohort of incident patients with FSGS was mainly represented by patients with a low degree of proteinuria, a characteristic which is associated with less progressive disease [26]. Therefore, the results of the present study cannot be extended to patients with more aggressive disease, such as those patients with the collapsing FSGS variant $[2,35]$.

In summary, we demonstrated that senescence is upregulated in both glomerular and tubular compartments in a cohort of adult patients with FSGS, and that $\mathrm{p} 16^{\mathrm{INK} 4 \mathrm{~A}}$ overexpression in the tubular compartment is associated with accelerated loss of renal function. Therefore, our results suggest that senescence, as expressed by $\mathrm{p} 16^{\mathrm{INK} 4 \mathrm{~A}}$ overexpression in the tubular compartment, contributes to accelerated loss of eGFR in FSGS. In addition, this study provides a clinical basis for in vitro studies of senescence regulatory molecules as a potential target for therapeutic intervention in a common clinical condition that is still associated with an unfavorable prognosis. With this regard, the estimate of $\mathrm{p} 16^{\mathrm{INK} 4 \mathrm{~A}}$ in kidney biopsies could also be considered a sensitive index of disease progression.

\section{Acknowledgement}

This study was supported by a grant from the Ministero dell'Università e della Ricerca Scientifica e Tecnologica (FIRB 2002).

\section{Statement of Ethics}

This study was approved by the Institutional Research Ethics Committee of Department of Internal Medicine, University of Genoa, Italy. This study was performed in compliance with the Helsinki Declaration. All individuals provided informed consent prior to their inclusion in the study.

\section{Conflict of Interest Statement}

There is no conflict of interest to disclose.

\section{Author Contributions}

D.V. studied senescence marker expression in kidney biopsies; F.V. and G.G. designed the study; G.S. described the histology of kidney biopsies; E.R. and L.C. collected clinical data; M.S., L.P., and A.C. analyzed the data; G.G., P.E., and D.V. wrote the manuscript; and F.C., D.P., and Ga.Ga. contributed to the discussion and edited the manuscript. All authors approved the manuscript. G.G. is the guarantor of this work and, as such, had full access to all the data in the study and takes responsibility for the integrity of the data and the accuracy of the data analysis.

References

1 Campisi J, d'Adda di Fagagna F. Cellular senescence: when bad things happen to good cells. Nat Rev Mol Cell Biol. 2007;8(9):72940.

2 Yang $\mathrm{H}$, Fogo AB. Cell senescence in the aging kidney. J Am Soc Nephrol. 2016;21(9): 1436-9.

3 Childs BG, Durik M, Baker DJ, van Deursen JM. Cellular senescence in aging and age-related disease: from mechanisms to therapy. Nat Med. 2015;21(12):1424-35.

4 Schmitt R, Melk A. Molecular mechanisms of renal aging. Kidney Int. 2017;92(3):569-79.

5 Schmitt R, Melk A. New insights on molecular mechanisms of renal aging. Am J Transplant. 2012;12(11):2892-900. 
6 Sis B, Tasanarong A, Khoshjou F, Dadras F, Solez K, Halloran PF. Accelerated expression of senescence associated cell cycle inhibitor p16INK4A in kidneys with glomerular disease. Kidney Int. 2007;71(3):218-26.

7 Verzola D, Gandolfo MT, Gaetani G, Ferraris A, Mangerini R, Ferrario F, et al. Accelerated senescence in the kidneys of patients with type 2 diabetic nephropathy. Am J Physiol Renal Physiol. 2008;295(5):F1563-73.

8 Liu J, Yang JR, He YN, Cai GY, Zhang JG, Lin LR, et al. Accelerated senescence of renal tubular epithelial cells is associated with disease progression of patients with immunoglobulin A (IgA) nephropathy. Transl Res. 2012; 159(6):454-63.

9 Kitiyakara C, Eggers P, Kopp JB. Twenty-oneyear trend in ESRD due to focal segmental glomerulosclerosis in the United States. Am J Kidney Dis. 2004;44(5):815-25.

10 Silva FG, Hogg RJ. Minimal change nephrotic syndrome-focal sclerosis complex. In: Tisher CC, Brenner BM, editors. Renal pathology with clinical functional correlations. Philadelphia: J Lippincot Company; 1989. p. 265-330.

11 Floege J, Amann K. Primary glomerulonephritides. Lancet. 2016;387(10032):2036-48.

12 D'Agati VD, Kaskel FJ, Falk RJ. Focal segmental glomerulosclerosis. N Engl J Med. 2011; 365:2398-411.

13 Fogo AB. Causes and pathogenesis of focal segmental glomerulosclerosis. Nat Rev Nephrol. 2015;11(2):76-87.

14 Coppo R, Camilla R, Porcellini MG, Peruzzi L, Gianoglio B, Amore A, et al. Saquinavir in steroid-dependent and -resistant nephrotic syndrome: a pilot study. Nephrol Dial Transplant. 2012;27(5):1902-10.

15 D'Agati VD, Alster JM, Jennette JC, Thomas DB, Pullman J, Savino DA, et al. Association of histologic variants in FSGS clinical trial with presenting features and outcomes. Clin J Am Soc Nephrol. 2013;8:399-406.

16 Prieto LI, Graves SI, Baker DJ. Insights from in vivo studies of cellular senescence. Cells. 2020;9(4):954.
17 Verzola D, Gandolfo MT, Ferrario F, Rastaldi MP, Villaggio B, Gianiorio F, et al. Apoptosis in the kidneys of patients with type II diabetic nephropathy. Kidney Int. 2007;72(10):126272.

18 Dimri GP, Lee X, Basile G, Acosta M, Scott G, Roskelley C, et al. A biomarker that identifies senescent human cells in culture and in aging skin in vivo. Proc Natl Acad Sci U S A. 1995; 92(20):9363-7.

19 Itahana K, Itahana Y, Dimri GP. Colorimetric detection of senescence-associated $\beta$ galactosidase. Methods Mol Biol. 2013;965:143-56.

$20 \mathrm{Xu}$ M, Pirtskhalava T, Farr JN, Weigand BM, Palmer AK, Weivoda MM, et al. Senolytics improve physical function and increase lifespan in old age. Nat Med. 2018;24(8):1246-56.

21 Kanno K, Kawachi H, Uchida Y, Hara M, Shimizu F, Uchiyama M. Urinary sediment podocalyxin in children with glomerular diseases. Nephron Clin Pract. 2003;95(3):c91-9.

22 Sharif K, Goyal M, Kershaw D, Kunkel R, Wiggins R. Podocyte phenotypes as defined by expression and distribution of GLEPP1 in the developing glomerulus and in nephrotic glomeruli from MCD, CNF, and FSGS. A dedifferentiation hypothesis for the nephrotic syndrome. Exp Nephrol. 1998;6(3):234-44.

23 Barisoni L, Kriz W, Mundel P, D’Agati V. The dysregulated podocyte phenotype: a novel concept in the pathogenesis of collapsing idiopathic focal segmental glomerulosclerosis and HIV-associated nephropathy. J Am Soc Nephrol. 1999;10(1):51-61.

24 Shankland SJ, Eitner F, Hudkins KL, Goodpaster T, D'Agati V, Alpers CE. Differential expression of cyclin-dependent kinase inhibitors in human glomerular disease: role in podocyte proliferation and maturation. Kidney Int. 2000;58(2):674-83.

25 Melk A, Schmidt BM, Takeuchi O, Sawitzki B, Rayner DC, Halloran PF. Expression of p16INK4a and other cell cycle regulator and senescence associated genes in aging human kidney. Kidney Int. 2004;65(2):510-20.
26 Rosenberg AZ, Kopp JB. Focal segmental glomerulosclerosis. Clin J Am Soc Nephrol. 2017;12(3):502-17.

27 Debacq-Chainiaux F, Erusalimsky JD, Campisi J, Toussaint O. Protocols to detect senescence-associated beta-galactosidase (SA-betagal) activity, a biomarker of senescent cells in culture and in vivo. Nat Protoc. 2009;4(12): 1798-806.

28 Liu WJ, Xu BH, Ye L, Liang D, Wu HL, Zheng YY, et al. Urinary proteins induce lysosomal membrane permeabilization and lysosomal dysfunction in renal tubular epithelial cells. Am J Physiol Renal Physiol. 2015;308(6): F639-49.

29 Weinberg RA. The retinoblastoma protein and cell cycle control. Cell. 1995;81(3):32330.

30 Serrano M, Lee H, Chin L, Cordon-Cardo C, Beach D, DePinho RA. Role of the INK4a locus in tumor suppression and cell mortality. Cell. 1996;85(1):27-37.

31 Berkenkamp B, Susnik N, Baisantry A, Kuznetsova I, Jacobi C, Sörensen-Zender I, et al. In vivo and in vitro analysis of age-associated changes and somatic cellular senescence in renal epithelial cells. PLoS One. 2014;9(2): e88071.

32 Goligorsky MS. Chronic kidney disease: a vicarious relation to premature cell senescence. Am J Pathol. 2020;190(6):1164-71.

33 Braun H, Schmidt BM, Raiss M, Baisantry A, Mircea-Constantin D, Wang S, et al. Cellular senescence limits regenerative capacity and allograft survival. J Am Soc Nephrol. 2012; 23(9):1467-73.

34 Baker DJ, Childs BG, Durik M, Wijers ME, Sieben CJ, Zhong J, et al. Naturally occurring p16(Ink4a)-positive cells shorten healthy lifespan. Nature. 2016;530(7589):184-9.

35 Viazzi F, Leoncini G, Pontremoli R. Global cardiovascular risk assessment in the management of primary hypertension: the role of the kidney. Int J Hypertens. 2013;542646: 2013. 